\title{
Glaucoma secondary to spherophakia/ectopia lentis and megalocornea
}

INSERM

\section{Source}

INSERM. (1999). Orphanet: an online rare disease and orphan drug data base. Glaucoma secondary to spherophakia/ectopia lentis and megalocornea. ORPHA:238763

Glaucoma secondary to spherophakia/ectopia lentis and megalocornea is a rare, genetic, non-syndromic developmental defect of the eye disorder characterized by congenital megalocornea associated with spherophakia and/or ectopia lentis leading to pupillary block and secondary glaucoma. Additional features may include flat irides, iridodonesis, axial myopia, very deep anterior chambers, miotic, oval pupils without well-defined borders, ocular pain and irritability manifesting as conjunctival injection, corneal edema and central scarring, as well as a high arched palate. 